\title{
FATORES DE SATISFAÇÃOE INSATISFAÇÃO ENTRE OS PACIENTES ASSISTIDOS PELO SUS
}

\author{
FACTORS THAT CAUSE SATISFACTION AND INSATISFACTION AMONG \\ PATIENTS ASSISTED BY SUS \\ FACTORES DE SATISFACCIÓN E INSATISFACCIÓN ENTRE LOS \\ PACIENTES ATENDIDOS POR EL SUS
}

\author{
Sérgio Ribeiro dos Santos' \\ Maria do Carmo Nunes de Lacerda ${ }^{2}$
}

\begin{abstract}
RESUMO: Este estudo foi desenvolvido com o propósito de identificar os fatores que causam satisfaçāo ou insatisfaçāo nos pacientes internos em hospitais conveniados com o Sistema Único de Saúde (SUS), com base na assistência prestada durante o periodo de internaçăo. A amostra foi constituida de cento e setenta pacientes. Para a coleta de dados, utilizou-se um questionário com quarenta e sete questōes fechadas. Os resultados obtidos revelaram diversos aspectos que comprometem a qualidade do serviço prestado, tais como: serviço médico, nutrição, enfermagem e o ambiente. Assim, conclui-se que há insatisfaçăo nos pacientes em relação aos serviços oferecidos pelo SUS.
\end{abstract}

PALAVRAS-CHAVE: fatores de satisfaçăo, serviços de saúde, qualidade total.

\section{INTRODUÇÃO}

A saúde é uma das necessidades individuais e coletivas que precisam de uma politica de governo centralizada nas questöes sociais. No Brasil, o desafio é grande, em face de uma permanente crise na assistência à saúde que, ao longo dos anos, foi se agravando com maior ou menor intensidade. Nesse cenário, surge o Sistema Único de Saúde (SUS), de caráter público, pautado na universalidade, integralidade e descentralizaçăo das açōes sanitárias, assim como no controle social.

O Brasil vivenciou uma intensa luta social pelo direito à saúde, no contexto de sua democratização, durante a década de 80 . Essa luta levou a Constituição de 1988 a reconhecer a saúde como direito universal do cidadão e dever do Estado. Dai a necessidade de ampliação do acesso a atenção à saúde, da promoção do maior número de pessoas e da diversificação nos serviços de saúde, através da unificação e descentralização, instituindo-se o SUS.(Giovanella,1996).

A transformação do sistema de saúde no Brasil, deu-se graças ao consenso existente entre os membros que compunham os órgãos governamentais, quanto à inadequação do antigo sistema de saúde, que tinha as seguintes caracteristicas: baixa cobertura assistencial à população, com segmentos populacionais excluidos do atendimento; desempenho desordenado dos órgãos públicos e privados, conveniados e contratados, acarretando conflitos entre esses setores; superposição de ações, baixa qualidade dos serviços oferecidos em termos de equipamentos e serviços profissionais, desperdicio de recursos e insatisfação

\footnotetext{
'Professor do Departamento de Enfermagem - DEMCAVUFPB. Mestre em Enfermagem.

${ }^{2}$ Enfermeira. Discente do curso de especializaçăo em Administração do Serviço de Enfermagem
} 
da população com os profissionais da área de saúde.(BRASIL,1990).

Diante dessa situação, associada a outros aspectos, tais como a caótica politica de saúde pública e dos serviços previdenciários de atenção médica, a desigualdade social e a exclusão da maioria da população, bem como a insatisfação da população com o atendimento à saủde, foram motivos que levaram a criação do SUS. (BRASIL, 1990).

O objetivo primordial do SUS é melhorar a qualidade da atenção à saúde no pais, rompendo com um passado de descompromisso social. Esse objetivo tem por base os seguintes principios doutrinários: Universalidade - garantia de atenção à saúde por parte do sistema a todo e qualquer cidadão. $O$ individuo passa a ter direito e acesso a todos os serviços públicos de saúde, assim como aqueles contratados pelo poder público. Eqüidade - desenvolvimento de ações e serviços em todos os niveis, de acordo com a complexidade que cada caso requeira. Integralidade - reconhecimento, na prática dos serviços, de que cada pessoa é um todo individual e integrante de uma comunidade. Do mesmo modo, as ações de promoção, proteção e recuperação da saúde formam também um todo indivisivel e não podem ser compartimentalizados (BRASIL, 1994).

Na prática, observa-se que o desempenho do SUS ainda está longe do modelo proposto, em que a população deve ter suas necessidades prontamente atendidas. Nós sabemos que isto não está acontecendo, pelo contrário, a cada dia é mais nítida a gravidade da situação, o sucateamento dos equipamentos, falta de recursos financeiros, programas de saúde isolados de uma politica social e a permanente desqualificação dos recursos humanos. Estes e outros problemas refletem o baixo indice de satisfação dos usuários do sistema.(Carvalho, 1996, Gillag, 1994).

A tese, satisfação do cliente como sinônimo de qualidade, (Campos, 1992, Malik, 1992, Mezomo,1993) é defendida por muitos autores que lidam com a administração, argumentando que é através do cliente que se avalia a qualidade dos serviços prestados. A satisfação do paciente constitui um valioso feedback que vai contribuir para refletir sobre a melhoria continua do trabalho em equipe. Assim, exige-se uma constante investigaçăo, na busca de identificar componentes que comprometem o desempenho da equipe de saúde e da administração hospitalar.

Para Berwick (1994) a qualidade da assistência nos serviços de saúde pode ser definida como satisfação das necessidades dos clientes. É para eles que devem ser dirigidas as estratégias na busca da qualidade. Os clientes devem ser ouvidos acerca da avaliação sistemática das atitudes dos profissionais da saúde, como também a respeito do impacto dos processos de tratamento sobre sua saúde.

Segundo Mezomo (1993), "as percepções dos pacientes são vitais e é por isto que elas devem ser pesquisadas com instrumentos adequados". As informações do paciente sobre a assistência que recebeu durante sua hospitalização são fundamentais, visto que delas dependem a análise sobre qualidade do serviço. Portanto, tratando-se de qualidade, deve-se conhecer as necessidades e os desejos do paciente, núcleo central do sistema de cuidados de saúde.

A qualidade pode existir a nivel dos fatos e na percepção das pessoas. A primeira diz respeito à visão do profissional que utiliza indicadores para quantificá-la. Já a qualidade na percepção das pessoas é a visão empirica dos fatos, um julgamento individual, subjetivo, sem critério técnico. Essa forma de observar e julgar é utilizada pelo usuário.

A impressão generalizada da opinião pública e dos usuários sobre o desempenho dos serviços públicos de saúde é de que o sistema é deficiente, com os seguintes problemas: cobertura insuficiente, desigualdade no atendimento, baixa qualidade dos serviços oferecidos em termos de equipamentos e serviços profissionais, baixa capacidade resolutiva, reduzido grau de satisfação por parte dos usuários e dos próprios trabalhadores e, como consequeência de tudo isso, elevado custo/beneficio do sistema em seu conjunto.(Santana, 1996).

Vez por outra, em nosso pais, ocorrem tragédias na área de saúde, provocando muitas 
mortes, refletindo o descaso das autoridades pela questão saúde no Brasil. Conseqüentemente, observa-se uma profunda deterioração nas instituições hospitalares que cada vez mais diminuem o número de atendimento aos pacientes conveniados com o SUS.

Diante de toda essa situaçăo, pode-se fazer o seguinte questionamento: a qualidade dos serviços prestados pelo SUS conduz à satisfação ou insatisfação nos pacientes internados nas instituiçōes hospitalares?

Motivados por esta questão, determinamos como objetivo para este estudo: identificar as causas de satisfação ou insatisfação, segundo a percepção dos pacientes internos em hospitais privados e filantrópicos conveniados com o SUS.

\section{METODOLOGIA}

O presente estudo caracteriza-se como exploratório descritivo e foi realizado com base no método quantitativo. Optamos por esta abordagem, uma vez que esse tipo de pesquisa tem como propósito observar, descrever e explorar os aspectos caracteristicos de uma determinada população.(Gil,1991).

O estudo foi desenvolvido em seis hospitais, localizados na cidade de João Pessoa-Pb, sendo três privados e três filantrópicos conveniados com o SUS.

A população constituiu-se de todos os pacientes internados nestes hospitais, por ocasião da coleta de dados, perfazendo um total de 270 (duzentos e setenta) pacientes. A amostra foi baseada na escolha aleatória dos pacientes, observando-se os seguintes critérios:

- o paciente precisava estar em condições de responder ao questionário e disposto a

participar da pesquisa;

- o paciente devia ter idade minima de quinze anos.

Os pacientes que preencheram esses critérios, mesmo os que estavam com alta hospitalar programada, puderam participar da amostra. Dessa maneira, alcançou-se um total de 170 (cento e setenta) pacientes.

Para a coleta de dados foi utilizado um questionário, através do qual se procurou captar a opinião dos pacientes em relação aos diversos aspectos da assistência recebida nas instituições conveniadas pelo SUS.

O referido instrumento foi composto por quarenta e sete questōes fechadas, contendo itens relacionados ao atendimento oferecido pelo hospital. O questionário foi aplicado, preliminarmente, junto a dez pacientes, a fim de se conhecerem possiveis dificuldades relativas à compreensão das perguntas. Após pré-análise dos resultados e constatadas as falhas, foram feitas as devidas reformulações no instrumento, mantendo alguns enunciados e explicando melhor outros.

Os dados coletados foram apurados e analisados através de medidas da estatistica descritiva, tais como frequência e percentagem. Para tanto, utilizou-se o pacote estatístico SPSSIPC.(1993).

\section{APRESENTAÇĀO E ANÁLISE DOS RESULTADOS}

Para a obtençăo dos resultados, foram coletados cento e setenta questionários, representando $62,9 \%$ da população em seis hospitais conveniados com o SUS.

A partir da estatistica descritiva, foi possivel identificar e agrupar as diversas variáveis por afinidade. Por exemplo: variáveis relacionadas à recepção, à enfermagem, aos médicos, à nutrição, ás condiçōes do ambiente de internação e ao hospital em geral. 
O Gráfico 1 apresenta a percepção dos pacientes em relação ao serviço de recepção dos hospitais investigados. De um modo geral, os resultados mostram um grau médio de satisfaçăo dos pacientes em relação a esse serviço. A recepção constitui a primeira impressão do paciente a respeito do hospital. Nesse aspecto, o hospital que apresenta um serviço de recepção organizado, ágil e que atende cordialmente ao cliente, gera uma expectativa positiva em relaçăo à assistência que prestará ao paciente.

\section{GRẢFICO 1 - Distribuição das variáveis relacionadas ao serviço de recepção}

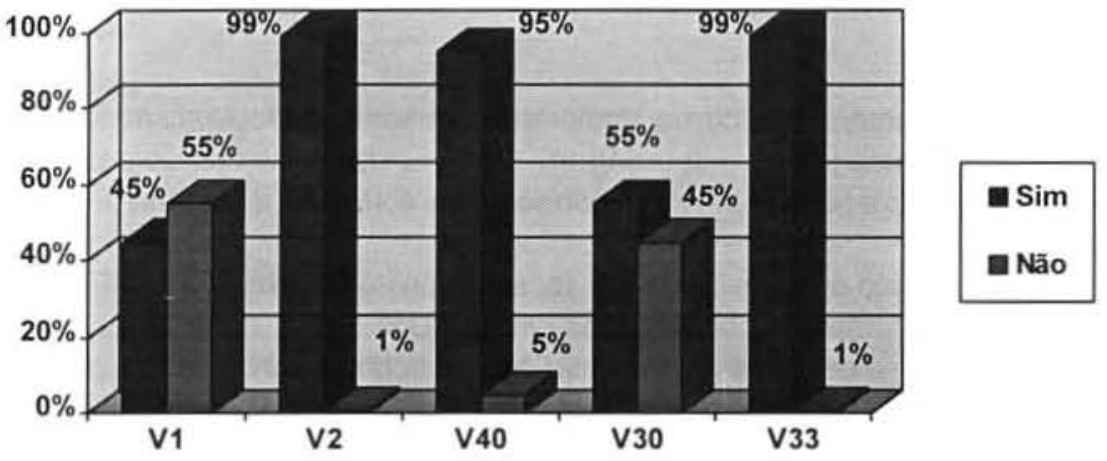

Fonte: Informaçōes fornecidas pelos pacientes internos em instituiçōes privadas e filantrópicas-Joāo Pessoa- $\mathrm{Pb}$.

V1 - Houve rapidez na sua admissão?

V2 - O sr(a) foi bem atendido na recepção?

V40 - O pessoal da recepção é atencioso?

V30 - Após seu internamento, o sr(a) e seus familiares foram informados sobre o horário do hospital para refeições e visitas?

V33 - O sr(a) acha que a recepção presta informações confiáveis aos visitantes?

Segundo Mezomo (1979), o ingresso no hospital exerce uma pressăo psicológica profunda, tanto no paciente, quanto nas pessoas que o acompanham. Para humanizá-lo devemos considerar as condiçōes materiais de recepção e a organização administrativa da mesma.

Apesar da satisfação dos pacientes com o serviço de recepção, eles ainda enfrentam problemas. De acordo com a nossa observação constatamos demora no atendimento e dificuldades para localizar o médico. Os hospitais que apresentam um serviço de recepção com essas deficiências podem criar uma imagem negativa junto à opinião pública.

Todavia, essa situação pode ser modificada se os hospitais investirem na melhoria desse serviço, através da informatização e treinamento do pessoal no trato com o público, na sinalização dentro do hospital para orientação do paciente e visitantes, porque a recepção é o cartão de apresentação do hospital.

O Gráfico 2, apresenta a percepção dos pacientes em relação ao atendimento médico, verificando-se, em geral, insatisfação.

As razões são diversas, destacando-se que $90 \%$ dos pacientes estão insatisfeitos com a falta de informações que deveriam ser prestadas pelo médico. Muitos pacientes alegaram que não recebem a devida atenção do médico. Eventualmente, quando recebem alguma informação, é de forma muito rápida, não satisfazendo as suas expectativas quanto à doença e ao processo de recuperaçăo, deixando-os inseguros e com muitas dúvidas a esclarecer. Os pacientes querem que os médicos tenham tempo suficiente para responder as suas questões, apresentar-Ihes 
explicaçōes sobre a doença, enfim, dar-lhes mais atenção.

GRÁFICO 2 - Distribuição das variáveis relacionadas ao atendimento médico

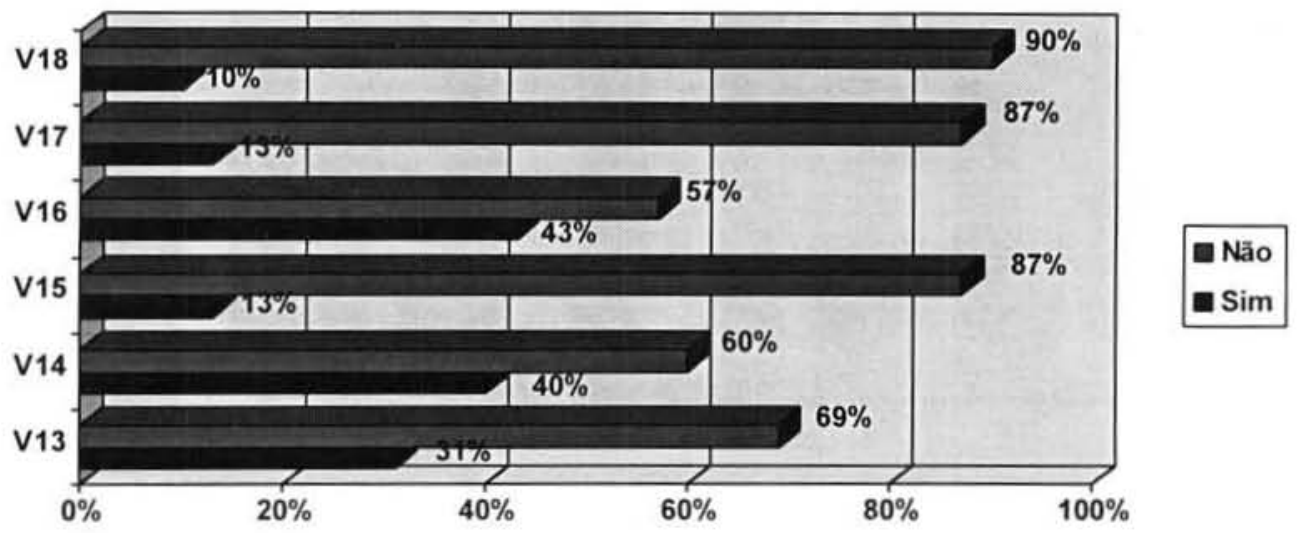

Fonte: Informaçōes fornecidas pelos pacientes internos em instituiçōes privadas e filantrópicas-Joăo Pessoa-Pb.

V13 - O tempo que o médico gasta com o sr(a) é suficiente?

V14 - O médico demonstra interesse em conhecer seus problemas e ajudá-lo?

V15 - O médico lhe dá informaçōes sobre a evoluçăo de seu tratamento?

V16 - O médico o visita diariamente?

V17 - O médico lhe dá tempo para expor seus problemas ou dúvidas?

V18 - O médico presta alguma informação a seus familiares?

A profissăo dos médicos, apesar das agruras atuais, continua fascinante. Ela atrai constantemente a atenção pública, que se situa entre extremos de admiração, louvor e respeito de um lado e desconfiança ou mesmo hostilidade do outro. Suporta com estoicismo as farpas dos mais ilustres escritores, configuradas na célebre frase de Voltaire: "O médico eficiente é aquele que distrai o paciente enquanto a natureza o cura". (Laudmann,1984).

É notório a confiança e consideração que o paciente deposita no médico e que parecem não ser ponderadas. Daí, a necessidade de um trabalho em equipe harmonizado, no qual o médico e os demais profissionais da saúde, devem estabelecer objetivos comuns e analisar criticamente, de forma continua, o desempenho alcançado, a fim de que possam desenvolver uma conduta profissional mais humanizada.

Nesse sentido, é imprescindivel um intenso trabalho educativo. Afinal, a prestação de serviço de saúde com qualidade e humanizada é uma questão de cidadania, é direito constitucional do brasileiro, é dever do Estado e obrigaçăo ética dos profissionais da saúde.

O Gráfico 3 contém a percepção dos pacientes em relação ao serviço de enfermagem, onde se constata um baixo nivel de satisfaçăo. 
GRÁFICO 3 - Distribuiçăo das variáveis relacionadas ao serviço de enfermagem

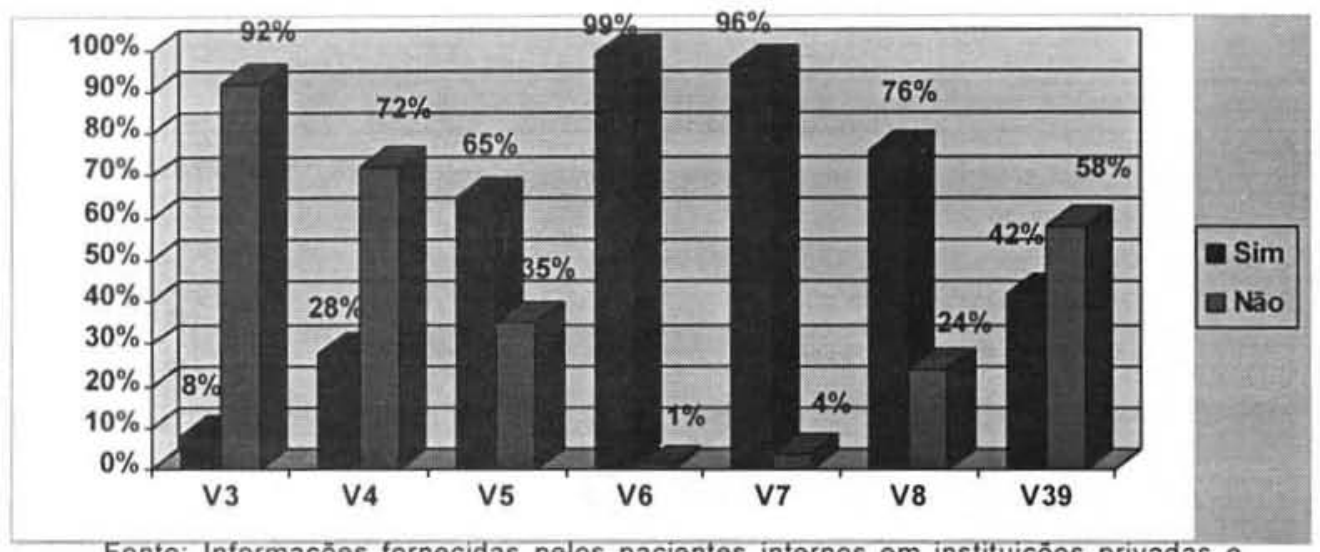

Fonte: Informaçōes fornecidas pelos pacientes internos em instituiçōes privadas e filantrópicas-Joăo Pessoa-Pb.

V3 - O sr(a) se sente seguro com os cuidados recebidos do pessoal de enfermagem? V4 - A equipe de enfermagem é atenciosa em relação às suas chamadas?

V5 - A equipe de enfermagem demonstra atenção para com as suas necessidades?

V6 - As(Os) enfermeiras(os) Ihe dão informaçőes relativas aos exames e tratamento?

V7 - As(Os) enfermeiras(os) procuram ajudá-lo em suas dúvidas ou preocupações?

V8 - A equipe de enfermagem é ágil nos cuidados prestado?

V39-O sr(a) pode comunicar-se facilmente com a equipe de enfermagem?

Esse conjunto de informaçöes apresentado pelos pacientes está relacionado a vários fatores característicos dos hospitais conveniados com o SUS, que explicam a situação, porém não justificam os fatos, por exemplo: a elevada taxa de ocupaçăo hospitalar, a imagem negativa do pessoal de enfermagem sobre a qualidade do serviço que presta à população, salários aviltados e falta de valorização dos profissionais de saúde, levam ao descrédito e põem em risco a populaçăo carente que utiliza os serviços do SUS.

O hospital que possui uma equipe de saúde que demonstra interesse e atençăo aos pacientes, considerando-os como prioridade nas açōes de enfermagem, caminha para alcançar a qualidade pela satisfação das necessidades dos requisitos e das expectativas do pacientes.(Azambuja,1994). Vale ressaltar que a enfermagem é o elemento básico desse processo, porque está envolvido com o paciente desde a sua internação, recebendo-o, assistindo$\mathrm{O}$, informando e preparando-o para o tratamento e a alta hospitalar. A partir desses procedimentos, cria-se um relacionamento de amizade e de confiança que contribui sensivelmente na recuperação do paciente.

Em tese, a enfermagem quando é bem treinada na área técnica, psicológica e educacional, proporciona uma assistência de qualidade. Infelizmente, essa năo é a realidade dos hospitais brasileiros, especialmente em João Pessoa-Pb. O desafio na busca da qualidade não termina com a satisfação do paciente, é preciso buscar também satisfação nos atores do processo. Portanto, concordamos com Azambuja(1994), quando define qualidade total como sendo a satisfação das necessidades, dos requisitos e das expectativas dos empregados.

Por outro lado, devemos esclarecer que numa empresa hospitalar, a satisfação é alcançada, quando se colocam à disposição do paciente serviços, informações e outras que este não espera encontrar. Quando se colocam também à disposição do profissional de saúde condições operacionais e técnicas compativeis com sua função, segurança e treinamento sistemático, 
remuneração adequada e estimulos motivacionais.

Em relação ao serviço de nutrição, verifica-se na Tabela 1 que há uma baixa satisfação dos pacientes. Apenas dois enunciados apresentaram niveis elevados de satisfação: $99 \%$ dos pacientes afirmam que as refeições eram servidas em horário conveniente e $91 \%$ declararam que as refeições eram servidas em quantidade suficiente. Todavia, os dados indicam que o serviço de nutrição limita-se apenas à preparação e distribuição dos alimentos.

Pode-se inferir que a satisfação dos pacientes com a alimentação pode estar relacionado ao estado de saúde, isso significa que uma pequena quantidade de comida pode parecer suficiente. Além disso, os pacientes não esperam que a comida do hospital seja de excelente qualidade e alguns até reclamam a falta de variedade e sabor.

Observa-se ainda que o pessoal responsável pelo serviço de nutrição parece não ter demonstrado interesse em dialogar com o paciente, informá-lo da sua dieta, ouvir suas necessidades alimentares e estabelecer um programa de educação alimentar durante sua permanência no hospital e preparação pós-alta.

Para garantir a aceitação da dieta pelo paciente, é necessário que ele e seus familiares sejam orientados quanto à dieta, sendo importante colocar e esclarecer os seguintes pontos: qual a dieta a ser seguida, as caracteristicas básicas da dieta, importância da dieta na terapia do paciente, alimentos proibidos e permitidos, tempo de duração da dieta.(Lima,1993).

Estas orientações devem ser dadas não só quando da alta do paciente, mas também durante sua permanência no hospital para garantir sua aceitação $e$, conseqüentemente, influir positivamente na recuperação do paciente.

TABELA 1 - Distribuição das variáveis relacionadas ao serviço de nutrição

\begin{tabular}{lrrrr}
\multicolumn{1}{c}{ Variáveis } & Sim & \multicolumn{2}{c}{ Năo } & \% \\
\hline V19. O sr(a) recebe informações sobre sua dieta? & 24 & $14 \%$ & 146 & $86 \%$ \\
V20. Há possibilidade de receber a alimentação escolhida? & 3 & $2 \%$ & 167 & $98 \%$ \\
V21. As refeições que lhe são servidas estão sempre aquecidas? & 96 & $56 \%$ & 74 & $44 \%$ \\
V22. As refeições são em quantidade suficiente? & 155 & $91 \%$ & 15 & $9 \%$ \\
V23. As refeições são muito repetidas? & 149 & $88 \%$ & 21 & $12 \%$ \\
V24. O sr(a) costuma deixar sobras nas refeições? & 164 & $86 \%$ & 24 & $14 \%$ \\
V25. As refeições o agradam? & 42 & $25 \%$ & 128 & $75 \%$ \\
V26. As refeições são servidas em horários convenientes? & 168 & $99 \%$ & 2 & $1 \%$ \\
V27. As refeições são variadas? & 33 & $19 \%$ & 137 & $81 \%$ \\
V28. Alguém lhe perguntou por que deixou parte da refeição? & 4 & $2 \%$ & 166 & $98 \%$ \\
\hline
\end{tabular}

A Tabela 2 mostra a percepção dos pacientes quanto às condições do ambiente de internação, ou seja, as enfermarias. A partir dos resultados apresentados, verifica-se que há uma tendência para insatisfação dos pacientes em relação às condições ambientais das enfermarias, isso se explica pela despreocupação dos hospitais conveniados com o SUS com o bem-estar do paciente e não buscando meios que possibilitem uma permanência hospitalar com um mínimo de conforto. Podemos provar essas afirmações, através da observação "in loco" nos hospitais investigados, nos quais existem nas enfermarias camas velhas com colchões desconfortáveis, que não amenizam a dureza da cama, além de lâmpadas queimadas que dificultam o trabalho dos profissionais de saúde.

Além disso, as enfermarias destinadas ao SUS dos hospitais conveniados foram projetados para receber os pacientes sem acompanhamento familiar. Por essa razão os hospitais 
dispõem de enfermarias com capacidade diversificada, podendo chegar até oito leitos. Paralelamente a essa situação, os hospitais procuram adotar como rotina, o horário de visitas, porém não oferecem condiçōes para acomodar os visitantes com conforto.

TABELA 2 - Distribuição das variáveis relacionadas às condições ambientais

\begin{tabular}{lrrrr}
\multicolumn{1}{c}{ Variáveis } & Sím & $\%$ & Năo & $\%$ \\
\hline V9. O sı(a) sente-se confortável na enfermaria? & 80 & $47 \%$ & 90 & $53 \%$ \\
V10. A sua enfermaria é limpa diariamente? & 150 & $88 \%$ & 20 & $12 \%$ \\
V11. As roupas estão sempre limpas? & 79 & $46 \%$ & 91 & $54 \%$ \\
V12. O sr(a) já observou se há insetos na enfermaria? & 106 & $62 \%$ & 64 & $38 \%$ \\
V31. Há acomodações e conforto para os visitantes? & 3 & $2 \%$ & 167 & $98 \%$ \\
V35. Há suficiente tranqüilidade e silêncio na sua enfermaria? & 141 & $83 \%$ & 29 & $17 \%$ \\
V36. A iluminação da sua enfermaria é suficiente? & 169 & $99 \%$ & 1 & $1 \%$ \\
V37. Há muito barulho nos corredores? & 95 & $56 \%$ & 75 & $44 \%$ \\
V38. O sr(a) tem meios de distração para o seu tempo livre? & 62 & $36 \%$ & 108 & $64 \%$ \\
\hline
\end{tabular}

A Tabela 3 apresenta situaçōes que indicam um conjunto de questionamentos relacionados aos aspectos gera do hospital. Percebe-se que existe um expressivo nivel de insatisfação dos pacientes com a assistência recebida nos hospitais.

TABELA 3 - Distribuição das variáveis relacionadas aos aspectos gerais do hospital.

\begin{tabular}{lrrrr}
\multicolumn{1}{c}{ Variáveís } & Sím & $\%$ & Nāo & $\%$ \\
\hline V29. O sr(a) acha que seus familiares são bem atendidos? & 156 & $92 \%$ & 14 & $8 \%$ \\
V32. A sua familia recebe informações sobre seu estado de saủde e & 23 & $13 \%$ & 147 & $87 \%$ \\
tratamento? & 127 & $75 \%$ & 43 & $25 \%$ \\
V34. Há preocupação da equipe de saủde com sua privacidade? & 60 & $35 \%$ & 110 & $65 \%$ \\
V41. O sr(a) tem acesso a aparelhos de comunicação dentro do hospital? & 66 & $39 \%$ & 104 & $61 \%$ \\
V42. O sr(a) toma a medicação na hora certa? & 130 & $76 \%$ & 40 & $24 \%$ \\
V43. Os resultados dos exames demoram muito? & 168 & $99 \%$ & 2 & $1 \%$ \\
V44. O material usado no seu tratamento é descartável? & 74 & $43 \%$ & 96 & $57 \%$ \\
V45. O sr(a) acha que este hospital o respeita e o valoriza como pessoa? & 75 & $44 \%$ & 95 & $56 \%$ \\
V46. O sr(a) recomendaria este hospital para seus amigos ou parentes? & 123 & $72 \%$ & 47 & $28 \%$ \\
V47. O sr(a) voltaria a se internar neste hospital, se necessário? & & &
\end{tabular}

De acordo com esses dados, pode-se constatar insatisfação dos pacientes quanto à assistência complementar prestada pelos hospitais, em termos de medicação e exames laboratoriais. Segundo declaração de alguns pacientes, a medicação fora do horário prescrito pelo médico acontece porque nem sempre os hospitais conveniados dispõem do medicamento. Diante desses fatos, é plausivel admitir que a morosidade na entrega dos exames laboratoriais e a falta de continuidade no tratamento provocada pela escassez de medicamentos, sejam alguns dos principais responsáveis pelo prolongamento do periodo de permanência dos pacientes nos hospitais conveniados com o SUS.

O hospital, sendo uma instituição prestadora de serviços ao ser humano, deve proporcionar condições de segurança no atendimento de suas necessidades, no intuito de obter eficiência em suas ações. (Lawand; Ruthes; Esteves 1993). 
Por outro lado, observam-se alguns fatores de satisfação, segundo a percepção dos pacientes em relação ao hospital, como por exemplo: o uso de material descartável no tratamento, preocupação com a privacidade $\mathrm{e} o$ atendimento às necessidades dos familiares. Todavia, há de se ressaltar que, através da observação direta, verificamos que a privacidade do paciente nem sempre é respeitada. É comum a realização de procedimentos médicos ou de enfermagem com o paciente na enfermaria e as portas abertas, sem nenhuma precaução em protegê-lo à exposição diante dos outros companheiros de enfermaria.

No que concerne às visitas, foi observado que, os familiares antes de se dirigirem aos seus parentes internados passam pelo serviço de recepção e muitos deles não são atendidos com a cordialidade desejada. Além disso, durante a maioria das visitas, há pouco ou nenhum contato com a equipe de saúde. Esse contato é indispensável, se levarmos em consideração a importância da comunicação e envolvimento dos familiares na recuperação do paciente.

Constata-se, através de pesquisa, que o adulto carente, em geral, não assume a desejada responsabilidade pela saúde. Aparenta ignorância sobre o assunto e pouco interesse em aprender. Fica claro a necessidade de uma atuação eficaz da equipe de saúde juntamente com a família, no sentido de tentar levá-lo a assumir responsabilidade pela sua saúde.(Manzolli,1983).

Observa-se ainda que $72 \%$ dos pacientes voltariam a se internar no mesmo hospital, se fosse necessário. Isso se explica pelo fato de tratar-se de uma clientela socialmente desfavorecida. Assim, qualquer ajuda, quando necessitam de uma assistência constitui a única alternativa, uma vez que não têm condições de buscar uma instituiçăo que ofereça uma assistência de melhor qualidade.

\section{CONSIDERAÇÕES FINAIS}

O estudo abordando a percepção dos usuários do SUS, sobre os serviços ofertados pelos hospitais conveniados, permitiu-nos a oportunidade de conhecermos o nivel de satisfação e insatisfação com este serviço.

No geral, verificou-se que há insatisfação entre os pacientes participantes deste estudo em relação aos seguintes fatores:

- médico com percentual médio de $75 \%$ de insatisfaçăo;

- nutrição com percentual médio de $52 \%$ de insatisfação;

Outros fatores apontados como de moderada satisfação foram os seguintes:

- enfermagem com percentual médio de $59 \%$ de satisfaçăo;

- ambiente(enfermaria) com percentual médio de $58 \%$ de satisfação;

- aspectos gerais do hospital com percentual médio de $57 \%$ de satisfação.

- único fator considerado satisfatório pelos pacientes foi a recepção dos hospitais com percentual médio de $78 \%$ de satisfação. Obviamente, há algumas variáveis isoladas que compõem o grupo de fatores identificados com elevado grau de satisfação, porém não representam em si a satisfação total dos pacientes.

Ao considerar esses resultados, observa-se que a situação é preocupante e merece uma reflexăo séria com decisōes resolutivas imediatas, uma vez que a qualidade é entendida como a capacidade que tem um serviço para atingir a satisfaçăo plena das necessidades e expectativas do cliente, colocando à sua disposição todas as facilidades que este não espera. Assim, dentro da perspectiva do modelo de Gestão da Qualidade Total no Serviço de Saúde, apresentamos algumas sugestões que poderão ser aplicadas nos hospitais conveniados com o SUS, na busca continua da melhoria da qualidade dos serviços:

1. Visivel envolvimento e comprometimento dos diversos niveis gerenciais com a qualidade do serviço. Isso inclui: comunicar-se com as pessoas, agir como modelo, ouvir as pessoas, ministrar e receber treinamento, demonstrar comprometimento com a qualidade. 
2. Implementar, de forma contínua e sistemática, uma cultura da qualidade. Isso inclui: envolver-se na avaliação da conscientização para Qualidade Total, envolver-se na avaliação e revisăo do progresso alcançado na Qualidade Total, avaliação e promoção dos funcionários em todos os niveis.

3. Reconhecer e valorizar os esforços e sucessos alcançados individualmente ou em grupo.

4. Dar apoio total a melhoria da qualidade, através do fornecimento de recursos e assistência apropriados.

5. Promover o envolvimento com clientes e fornecedores.

6. Traçar politicas e estratégias baseadas no conceito da Qualidade Total.

7. Melhorar as habilidade e capacitação da equipe de saúde, através da elaboração e implementação de planos de treinamentos. Total.

8. Elaborar estratégias de informação que sejam compativeis ao esforço para a Qualidade

9. Estimular a inovação e a criatividade no processo de melhoria.

10. Desenvolver uma efetiva comunicaçăo de cima para baixo(top down) e de baixo para cima (bottom-up).

O impacto dessas medidas nos hospitais conveniados pelo SUS será percebida pela sociedade como um todo. Essa mentalidade de cuidar da saúde do individuo buscando a satisfação de suas expectativas e necessidades contribuirá para a melhoria da qualidade de vida. Além disso, outro indicador de impacto social para os hospitais, incluem:

- a minimização de reclamaçōes e processos contra a instituição; e,

- a redução nas infraçōes do código ético profissional.

ABSTRACT: This study has the purpose to identify the factors that cause satisfaction and insatisfaction to the patients who are interns in hospitals which have agreements with "Sistema Ünico de Saúde SUS", based on the assistency rendered during the period of internment. The samples were constituted of 170 patients. To obtain the data, there was used a questionary containing 47 closed questions. The results obtained revealed several aspects that compromise the quality of the service rendered, such as: service doctors, nutrition, nurse and the enviroment. Thus, concludes there is insatisfaction of the patients with the service offered by SUS.

KEYWORD: factores of satisfaction, service of Health, total quality

RESUMEN: El propósito de este estudio fue identificar los factores que causan satisfacción o insatisfacción en los pacientes internados en hospitales que mantienen convenio con el Sistema Único de Salud (SUS). La muestra fue constituida por ciento y sesenta pacientes. Para obtener los datos, se utilizó un cuestionario con cuarenta y siete preguntas cerradas. Los resultados revelaron diversos aspectos que comprometen la calidad del servicio prestado, tales como: servicio médico, nutrición, enfermeria y ambiente. Se concluye, asi, que existe insatisfacción de los pacientes en relación a los servicios ofrecidos por el SUS.

PALAVRAS LLAVE: fatores de satisfacción; servicios de salud, calidad total. 


\section{REFERÊNCIAS BIBLIOGRÁFICAS}

AZAMBUJA, Telmo Travasso. Metodologia para auto-avaliação da GQT. Rio de Janeiro: Qualitymark, 1994.

BERWICK, D. M. Melhorando a qualidade dos serviços médicos, hospitalares e da saúde. Sāo Paulo: Markon Books, 1994.

BRASIL. Ministério da Saúde. Coordenação de Informação, Educação e Comunicação. Núcleo de Estudo em Saúde Pública. Incentivo à participação popular e controle social no SUS: textos técnicos para conselheiros de saúde. Brasilia, 1994.

BRASIL. Ministério da Saúde. Secretaria Nacional de Assistência Técnica à Saúde. ABC do SUS: doutrinas e principios. Brasilia, 1990.

CAMPOS, V. F. Controle da qualidade total. Rio de Janeiro: Block, 1992.

CARVALHO, R. 10 anos de SUS: aniversário sem comemoraçăo. Revista Prodoctor Resident, São Paulo, v. 3, n. 5, p. 8-9, set./out. 1996.

CSILLAG, J. M. Opção pela qualidade total em serviço público: ação e modernização. São Paulo: Qualitymark, 1994.

GIL, A. C. Como elaborar projetos de pesquisa. São Paulo: Atlas, 1991.

GIOVANELLA, L. Eqüidade em saúde no Brasil. Saúde em debate, Brasilia, v. 1, n. 49-50, p. 13, dez.l mar. 1996.

LANDMANN, Jayme. A outra face da medicina - um estudo das ideologias médicas. Rio de Janeiro: Salamandra, 1984.

LAWAND, Elvira Maria P.; RUTHES, Rosa M.; ESTEVES, Silvia. O gerenciamento de materiais e medicamentos e a qualidade da assistência de enfermagem em centro cirúrgico. Revista Hospital - Adm. e Saúde, São Paulo, v. 17, n. 1, p. 37-41, jan./fev. 1993.

LIMA, Maria Lúcia C. R. A importância da nutrição clínica na terapia. Revista Hospital - Adm. e Saúde, São Paulo, v. 17, n. 5, p, 271-5, set./out. 1993.

MALIK, A. N. Desenvolvimento de recursos humanos, gerência de qualidade e cultura das organizaçōes de saúde. Revista Adm. Emp., São Paulo, v. 32, n. 4, p. 32-41, set./out. 1992.

MANZOLLI, Maria Cecilia. Relacionamento em enfermagem - aspectos psicológicos. São Paulo: Savier, 1983.

MEZOMO, J. C. Hospital humanizado. São Paulo: CEDAS, 1979.

MEZOMO, J. C. Qualidade na relação hospital-paciente. Revista Hospital - Adm. e Saúde, São Paulo, v. 17, n. 1, p. 17 , jan./fev. 1993.

SANTANA, J. P. Desenvolvimento gerencial no SUS: demandas e perspectivas. Revista Espaço para a saúde, Curitiba, v. 5 , n. 5, p. 13, set. 1996.

SPSS Inc. SPSS for Windows - advanced statistics. Release 6.0, SPSS Inc, Chicago, 1993. 